\title{
Update on triple-negative breast cancer: prognosis and management strategies
}

This article was published in the following Dove Press journal:

International Journal of Women's Health

21 September 2012

Number of times this article has been viewed

\section{Olivier Brouckaert \\ Hans Wildiers \\ Giuseppe Floris \\ Patrick Neven}

Multidisciplinary Breast Centre, UZ Leuven, Leuven, Belgium
Correspondence: Olivier Brouckaert Herestraat 49, 3000 Leuven, Belgium Tel $+32 \quad 16344634$

Fax +3216344629

Email olivier.brouckaert@uzleuven.be

\begin{abstract}
Triple negative breast cancer (TNBC) is a heterogeneous disease comprehending different orphan breast cancers simply defined by the absence of ER/PR/HER-2. Approximately $15 \%-20 \%$ of all breast cancers belong to this phenotype that has distinct risk factors, distinct molecular features, and a particular clinical presentation and outcome. All these features will be discussed in this review. The risk of developing TNBC varies with age, race, genetics, breastfeeding patterns, and parity. Some TNBC are very chemo-sensitive and the majority of patients confronted with and treated for TNBC will never relapse. Some (histological) subgroups of TNBC may have good prognosis even in the absence of chemotherapy. Distinct molecular subgroups within TNBC have been defined now as well. In case metastatic relapse occurs, this is usually within 5 years following surgery, and survival following metastatic relapse is shorter compared to other breast cancer subtypes; treatment options are few and responses lack durability. Novel drug targets and new biomarkers are needed to improve breast cancer care for patients presenting with TNBC. Further molecular/biological unraveling of TNBC is needed.
\end{abstract}

Keywords: breast cancer, triple negative, review

\section{Introduction}

Breast cancer remains the most frequently diagnosed female cancer worldwide and the leading cause of cancer death, despite screening and improvements in adjuvant treatment. ${ }^{1,2}$ Breast cancer is a clinical heterogeneous disease encompassing about 15 different types of carcinomas, which are for therapeutic reasons, further subclassified according to their estrogen receptor (ER), progesterone receptor (PR), and human epidermal growth factor receptor 2 (HER2) status. For the majority of patients, targeted therapies against one of the abovementioned targets are available. These treatment options are absent in patients diagnosed with tumors lacking ER, $\mathrm{PR}$, and HER2. These breast carcinomas are therefore referred to as triple negative breast cancers (TNBC).

TNBC represent a consistent subgroup of breast cancers with heterogeneous clinical presentation, clinical behavior, histology, and response to therapy. Awareness of TNBC was recently increased by the discovery of the intrinsic molecular subtypes in breast cancers with gene expression profiling experiments. At least five molecular categories (ie, luminal A/B, HER2-like, normal breast-like, and basal-like) have been repeatedly identified in breast cancer, each with prognostic significance. ${ }^{3}$ TNBC fall mostly in the so-called basal-like subtype, however this classification system presents some limitations in regard to accuracy, interobserver variability, and costs for analysis, preventing their introduction into the clinic. Therefore, more easy to use immunohistochemical 
surrogate definitions of molecular subtypes have been implemented into international guidelines. ${ }^{4}$

We will discuss definitions, epidemiology, risk factors, clinical and pathological characteristics, and management of TNBC. We conducted a PubMed search in the English literature using the terms "triple negative", "breast cancer", and "basal", and selected those articles that seemed relevant for this review.

\section{Definitions}

The terms "TNBC" and "basal-like breast cancer" are often used interchangeably, which can be confusing to the reader; however, despite the fact that most TNBC are basal-like, the two definitions are not synonymous.

The diagnosis of TNBC is an immunohistochemical orphan definition, characterized by the lack of expression for ER, PR, and HER-2. ${ }^{4}$ However methodological inconsistencies and use of different definitions for determining ER, PR, and HER2 status yield different results in phenotyping TNBC worldwide..$^{5-10}$ The joint American Society of Clinical Oncology (ASCO) and College of American Pathologist (CAP) guidelines for the assessment of ER, PR, and HER2 will likely result in a better standardization. ${ }^{11}$ Furthermore, the use of a $1 \%$ threshold for ER and PR positivity will most likely reduce the proportion of cases diagnosed as TNBC. ${ }^{11}$ Adherence to these guidelines is crucial since false negative/positive results for ER, PR, and HER2 have been reported to occur in up to $15 \%-20 \%$ of patients, potentially leading to unjustified withholding of endocrine treatment (undertreatment) or unnecessary overtreatment (cytotoxic chemotherapy) in some patients. ${ }^{12,13}$

The existence of breast cancers expressing myoepithelialspecific cytokeratins (also known as basal cytokeratins) dates back to the second half of the 80 s. ${ }^{14,15}$ However, it was only after the molecular revolution introduced by the seminal work of Perou et al that the term basal-like came into widespread use. $^{3}$ Thus, the term basal-like refers to a molecular definition, and describes those tumors that, at the transcriptomic level, show a profile similar to that encountered in basal/myoepithelial cells of the normal breast (ie, expression of mRNA of basal keratins). Because of the complexity and the cost of gene expression profiles, a number of studies have provided diverse immunohistochemical surrogate definitions for basallike breast cancers. ${ }^{16-20}$ Immunohistochemical introduction of basal cytokeratines (CK5 and CK6) and/or epidermal growth factor receptor 1 (EGFR1) can identify up to $81 \%$ of basallike breast cancers in one series. ${ }^{19}$ Further addition of CK14 and 17 has also been proposed. ${ }^{21}$ The lack of a standardized immunohistochemical panel, and standardized cut-off values to identify basal-like breast cancers within TNBC hampers its clinical usefulness. Currently the term "basal-like breast cancer" in diagnostic pathology reports does not lead to any clinical direct action and therefore is best avoided, unless for prognostic purposes.

A remarkable discrepancy between immunohistochemical and molecular classification of breast carcinomas is often observed. Although approximately $40 \%-80 \%$ of TNBC will cluster in the molecular basal-like compartment, around $20 \%-60 \%$ will be allocated to other intrinsic phenotypes (ie, Luminal A, Luminal B, Luminal-HER2, HER-2 like, claudin-low, normal-breast like), with different biology. ${ }^{18,22-26}$ For example, claudin-low breast cancers are a TNBC subtype biologically closely related to mammary stem cells (poorly differentiated) that may be enriched in BRCA pathway alterations. ${ }^{27}$ They have low expression of genes involved in tight cell junctions (including E-cadherin), almost always have an intense immune infiltrate, and often exhibit features of epithelial-mesenchymal transition. ${ }^{27}$ Vice versa, molecularly defined basal-like breast cancers might show immunohistochemical expression of ER, PR, and/or HER2 in a substantial number $(20 \%-40 \%)$ of cases. ${ }^{28-30} \mathrm{New}$ data have recently emphasized that the molecular complexity within TNBC constitutes more than basal versus non-basal TNBC. ${ }^{31}$ Recent transcriptome analysis from a large number of TNBCs from 21 independent studies identified six stable and biologically different clusters of TNBC exhibiting unique gene expression patterns and gene ontologies. ${ }^{31}$ These include two basal-like clusters (enriched in cell cycle and DNA damage response genes), two mesenchymal-like clusters (enriched in cell differentiation, epithelial-mesenchymal transition, and growth factor pathways), an immunomodulatory cluster (enriched in cell surface antigens, receptors, and signal transduction genes), and a luminal cluster (driven by androgen receptor signaling). ${ }^{31}$

\section{Epidemiology and risk factors}

The risk of developing TNBC varies with age, race, genetics, waist/hip ratio, breastfeeding patterns, and parity. Several population-based studies have shown that TNBC often presents at a younger age and more frequently in African American women and black ethnicities. ${ }^{18,32-35}$ A large study of the California Cancer Registry revealed that women with TNBC are significantly more likely to be aged $<40$ years, that non-Hispanic black (compared to white) women are twice as likely to be diagnosed with TNBC, and that the incidence of TNBC was twice as high as the incidence of 
other breast cancer subtypes. ${ }^{32}$ In the Carolina Breast Cancer Study, the prevalence of TNBC or basal-like breast cancers was $39 \%$ in premenopausal and $14 \%$ in postmenopausal African American women (compared with 16\% in nonAfrican American women). ${ }^{18,36}$

In hereditary breast and ovarian cancer syndromes, there is a well-established association between deleterious BRCA-1 mutation status and the risk of developing TNBC. ${ }^{37}$ BRCA-1 is a tumor suppressor gene involved in doublestrand DNA break repair and BRCA-1 deficiency results in higher genomic instability and tumor genesis. The lifetime risk of developing breast cancer in patients with hereditary breast and ovarian cancer syndromes may be as high as $50 \%-85 \%$, but the risk greatly varies depending on the patient's age, hormonal status (first age at menarche, etc), familial/genetic predisposition, and breast density. ${ }^{38}$ As few as five single nucleotide polymorphisms can modify breast cancer penetrance from $95 \%$ down to $45 \% .{ }^{39}$ Up to $75 \%$ of breast cancers developing in BRCA-1 carriers are TNBC, basal-like, or both. ${ }^{40,41}$ Young age at breast cancer diagnosis, and/or medullary (or medullary-like) histology and high mitotic activity (above 100 mitosis in ten high power fields) may hint towards BRCA-1 mutational status. ${ }^{42}$

Patients younger than 50 years diagnosed with TNBC but lacking a specific familial predisposing history are carriers of BRCA- 1 mutations in $10 \%-30 \%$ of cases. ${ }^{43,44}$ This observation may be important for the elaboration of genetic testing guidelines. ${ }^{45}$ Furthermore, a considerable (20\%) proportion of TNBC patients without the somatic BRCA-1 mutations may still have impaired DNA repair mechanisms due to other abnormalities in the BRCA pathway, ${ }^{46-52}$ (also referred to as BRCA-ness; ie, loss of heterozygosity of genomic regions encompassing these genes, BRCA-1 promotor methylation). The specific genomic instability in BRCA-1 (and 2) carriers may provide specific therapeutic opportunities (ie, platinumtype drugs that generate double-stranded DNA breaks or poly (adenosine diphosphate ribose) polymerase (PARP) inhibitors that prevent repair of single-strand DNA breaks).

Interestingly, although regarded as an endocrine insensitive disease, several hormonal alterations throughout a woman's life are associated with an increased risk of developing TNBC. Parity and young age at first full-term pregnancy increase the risk of developing TNBC but breastfeeding, a longer duration of breastfeeding, and an increasing number of children breastfed, all reduce the risk of developing TNBC. ${ }^{36}$ Some studies did not find an association between parity and breast cancers being more likely to be TNBC ${ }^{53,54} \mathrm{~A}$ higher waist/hip ratio is associated with an increased absolute risk for developing TNBC irrespective of menopausal status. ${ }^{36}$

\section{Clinical and pathological presentation}

TNBC usually presents at ages younger than that at which population-based organized breast cancer screening programs are offered. The majority of patients diagnosed with TNBC will therefore present with a palpable tumor. Among woman attending population-based organized breast cancer screening, TNBC will more likely present as an interval cancer (between two organized mammography screening rounds). ${ }^{55,56}$

Radiological features of TNBC are variable, although several reports describe typically a well-circumscribed mass, absence of spiculated margins, absence of microcalcifications, and/or an echogenic halo. ${ }^{57-59}$ High malignant intensity signals are characteristic both on magnetic resonance imaging or positron emission tomography. In one study, 18 patients with TNBC received positron emission tomography with F-18 fluoro-deoxyglucose and all tumors exhibited focally enhanced uptake, suggesting high sensitivity of positron emission tomography in TNBC. ${ }^{60}$

Histologically, TNBC are heterogeneous, being mostly invasive ductal carcinomas of no special type. In about $90 \%$ of the cases, TNBC are poorly differentiated with high proliferative activity and large primary tumor size. ${ }^{18,23,61}$ Microscopically, TNBC frequently show pushing borders associated with central necrosis, and a variable degree of lymphocytic infiltration. ${ }^{40,41}$ High-grade TNBC often present a dismal prognosis.

Special types of TNBC include medullary, metaplastic, secretory, adenoid cystic, invasive lobular carcinomas, apocrine/histiocytoid carcinomas, and carcinomas arising in microglandular adenosis. Recognition of special types of TNBC is of utmost importance since some of them are associated with better prognosis and indolent clinical course, such as adenoid cystic and secretory carcinoma. These low-grade TNBC (as compared to high-grade TNBC) carry relatively simple genomes and are characterized by specific chromosomal translocations resulting in chimeric fusion genes. The ETV6-NTRK3 and MYB-NFIB fusion genes have been recently described in secretory and adenoid cystic carcinomas, respectively. ${ }^{62,63}$ In Azoulay's series ( $\mathrm{n}=18$, median follow-up 6.5 years, one patient died of disease) adenoid cystic TNBCs had excellent outcomes even in the absence of adjuvant chemotherapy, and on reviewing the literature $(n=219$ adenoid cystic TNBC cases), they found a 3\% breast 
cancer specific death rate, although information on adjuvant treatment was lacking. ${ }^{64}$ Despite the histological features of classical medullary carcinomas (ie, highly proliferative, poorly differentiated carcinomas), these tumors frequently carry a good prognosis. In a series of medullary carcinomas $(n=41)$, high radiosensitivy was suggested $(7 \%$ of the patients had a complete response after a dose of 55-60 Gy) and chemotherapy had no effect on the rate of recurrence or survival (6-year local recurrence-free survival, metastasisfree survival, and survival rates were $86 \%, 83 \%$, and $83 \%$, respectively). ${ }^{65}$ Another series of medullary carcinomas $(n=71)$, also presented with good outcomes (10-year distant metastasis-free survival of $81.4 \%$ ) with chemotherapy only given to a minority $(n=11) .{ }^{66}$ Good outcomes $(14$-year distant recurrence-free interval of $89 \%$ for ER-negative medullary breast cancer) were also noticed in the International Breast Cancer Study Group (IBCSG) $(\mathrm{n}=127)$, but almost 70\% received adjuvant chemotherapy. ${ }^{67}$ High-grade metaplastic carcinomas may be resistant to systemic cytotoxic therapy and are associated with poor prognosis while low-grade metaplastic breast cancers may have better prognosis (ie, fibromatosis-like carcinoma). ${ }^{68,69}$

The relation between TNBC and lymph node status is less clear. Some authors found no relation, others found a negative association, and some found a positive association. ${ }^{40,55,70-72}$ Whatever the relation between TNBC and lymph node status, the lack of a relationship between increasing tumor size and lymph node involvement in TNBC suggests that these breast cancers preferentially spread hematogenously, giving rise to metastatic deposits in brain and lungs. ${ }^{73}$

\section{Prognosis and prognostic variables}

The discovery of the intrinsic breast cancer phenotypes was associated with differences in outcome and there is a unique recurrence pattern for "basal-like" and TNBC compared to other phenotypes, such as ER-positive tumors., ${ }^{3,55}$ Relapse rates are particularly high during the first years following surgery with a peak recurrence risk 3 years post-surgery in TNBC; afterwards, the recurrence risk rapidly declines. ${ }^{55} \mathrm{By}$ contrast, in ER-positive breast cancers, more than 50\% of recurrences are recorded between 5 and 10 years after the first surgery. ${ }^{74}$ In the long term, TNBC have intermediate outcomes, and more events will occur in high-grade ERpositive breast cancers. ${ }^{24,74,75}$

Whether TNBC is associated with an increased risk for locoregional relapse remains debatable, but some data suggest that both TNBC as well as HER-2 overexpressing breast cancers are at increased risk for locoregional relapse, also following mastectomy. ${ }^{76-78}$ The risk of developing subsequent distant metastasis and death following locoregional recurrence is higher in TNBC compared to other subtypes. ${ }^{79}$

Survival after metastatic relapse is shorter in TNBC compared to other subtypes. In part, this can be understood from the predilection for visceral and lung metastasis compared with ER-positive breast cancers that are more likely to relapse in bone and skin. ${ }^{75,80,81}$ Women with TNBC are at increased risk of developing brain metastasis (10\%-30\% depending on whether autopsy reports are considered) and median survival after brain metastasis is shorter compared with patients developing brain metastasis from other breast cancer phenotypes. ${ }^{82-84}$

The prognostic value of classical pathological variables such as tumor grade, lymph node status, and tumor size, could be impaired in TNBC. Indeed, most TNBC are high grade, and first generation prognostic molecular assays, which are driven mainly by proliferation, did not show prognostic value in TNBC. ${ }^{85}$ In contrast, Ki67 stainings in TNBC have been suggested to carry prognostic information in some reports but not in others. ${ }^{86,87}$ Small (cT1a/b) node-negative TNBC are potentially aggressive as well. ${ }^{88}$ Despite the abovementioned issues, the Nottingham Prognostic Index (NPI) has been reported to be useful in TNBC. ${ }^{89}$

Many other pathological prognostic variables (ie, lymphovascular/perivascular invasion, androgen receptor, e-cadherin) have been studied, mainly in retrospective cohorts, and therefore their use in daily clinic is not recommended. ${ }^{90-93}$ Interestingly, the recently reported molecular heterogeneity within TNBC might be concordant with some of these previously reported pathological variables. As such for example, Claudin-low TNBC seem to express less e-cadherine, some TNBC show an androgen signalling pathway whereas others mainly show an immune signature. . $^{31,94}$ In the past already, tumor lymphocyte infiltration in TNBC has been associated with more favorable prognosis before. ${ }^{22,95}$ Furthermore, an immune response gene module has been correlated with achieving pathological complete remission (pCR) in ER-negative breast cancer. ${ }^{96}$

Many studies have demonstrated the association between pCR and good prognosis, but the prognostic value of pCR was recently shown to be limited to certain breast cancer subtypes only (ie, TNBC, non-Luminal HER2-like, and Luminal B [HER2 negative]). ${ }^{97}$ Allowing no residual tumor burden in breast nor in lymph nodes provided superior prognostic information compared to other definitions. ${ }^{97}$ Anthracycline or anthracycline-taxane-based regimens in TNBC allow achieving pCR rates up to $20 \%-45 \%$ and these patients exhibit 
excellent prognosis, comparable with non-TNBC patients (achieving pCR) ${ }^{80,97-100}$ Although adjuvant treatment remains the gold standard, neoadjuvant treatment can be considered to downstage large TNBC or lymph node-positive TNBC, and for patients willing to participate in neo-adjuvant trials exploring the efficacy of novel (additional) drugs. These trials use pCR as a substitute outcome variable, although it remains to be determined what increments in pCR (like recently shown by adding bevacuzimab [Avastin ${ }^{\circledR}$; Roche-Genentech, Basel, Switzerland] to standard chemotherapy) translate into improved survival. ${ }^{97,101}$

Ethnicity has also been reported an independent prognostic variable with black women having inferior prognosis. ${ }^{18,32}$ The prognostic role of histology and lymph node status has been discussed earlier in this manuscript.

\section{Treatment Locoregional}

Locoregional treatment of TNBC is no different than for other invasive breast cancers. Although surrogate basallike breast cancer and TNBC have been suggested to have inferior 10-year locoregional outcomes compared to other subtypes, there are no surgical implications, since it was found to be true both following breast conserving surgery and mastectomy. ${ }^{76-78}$ Breast-conserving surgery remains the standard in small cT1 and some cT2 breast cancers compared to mastectomy for larger tumors, multifocal/ multicentric tumors, and in cases of involved section margins after previous breast-conserving surgery. Women with large TNBC may achieve higher rates of pCR following neoadjuvant chemotherapy, allowing breast-conserving surgery. ${ }^{80,98-100}$ Guidelines for adjuvant radiotherapy are no different than in other breast cancer subtypes. One specific consideration regarding locoregional treatment in TNBC is the option for prophylactic surgery in patients with BRCA-1 mutations.

\section{Chemotherapy in the (neo-)adjuvant setting}

Chemotherapy is the only systemic treatment to improve disease outcomes following the diagnosis of a TNBC, since a target is missing. TNBC can be highly sensitive to chemotherapy, as demonstrated by high rates of $\mathrm{pCR}$ following neoadjuvant chemotherapy. ${ }^{80,98-100}$

In the adjuvant setting, there is no proof that some chemotherapeutic agents are superior to others in function of a particular breast cancer. ${ }^{100}$ Anthracycline/taxane-based regimens constitute today's standard regimen for patients not participating in clinical trials. ${ }^{102}$ Previously, anthracycline-containing regimens have demonstrated their superiority compared to cyclophosphamide, methotrexate, and fluorouracil-containing regimens also in TNBC adjuvant trials. ${ }^{103,104}$ Later, addition of taxanes to an anthracycline-based regimen resulted in improved disease-free survival and overall survival, independently of ER expression. ${ }^{105,106}$ Anthracycline/taxane-based chemotherapy regimens have been shown to be highly active also in TNBC. ${ }^{98}$

As previously stated, the specific genomic instability in BRCA-1 carriers may provide specific therapeutic opportunities in TNBC. Platinum salts (ie, cisplatin) bind to DNA, causing DNA cross-linking. These double-stranded DNA breaks elicit DNA repair mechanisms (homologous recombination or nonhomologous end joining). ${ }^{102,107}$ The lack of this repair mechanism in BRCA-1 (and 2) mutant patients (that are frequently TNBC) turns cells into apoptosis rather than repair. Striking pCR rates $(72 \%-90 \%)$ have been reported in BRCA-1 mutation carriers following single-agent cisplatin neoadjuvant treatment, but the number of patients included in these studies was limited ( $n=10$ and $n=25)$ or data were retrospective in nature $(\mathrm{n}=102) .{ }^{108-110}$ In non-BRCA-1 mutant TNBC, the efficacy of platinum remains a subject of further study. Unfortunately, a larger and randomized Phase II trial ( $\mathrm{n}=94$ TNBC patients) could not find an increased $\mathrm{pCR}$ rate following the addition of carboplatinum to an anthracycline/ taxane-based regimen. ${ }^{11}$

\section{Chemotherapy in advanced TNBC}

Metastatic relapse in TNBC is associated with a paucity in treatment options through the absence of ER/PR/HER-2. Although discordances in receptor status between the primary breast tumor and the metastatic lesion have been reported for ER, PR, and HER-2, few patients with TNBC will gain extra treatment options. ${ }^{112}$ Confirmatory biopsies of metastatic relapse in breast cancer are however, recommended. Receptor status switch may represent a change in biology, although the possibility of false-negative staining results in the primary breast cancer should be ruled out. In the prospective series of Amir et al, two of 23 women with initial TNBC were found to have receptor discordance on the metastatic biopsy. ${ }^{112}$ Both represented false-negative staining and therefore true receptor discordance is an unlikely event in patients with TNBC. Reanalysis of the primary tumor in these women is recommended.

Chemotherapy remains the backbone of systemic treatment in TNBC. Since the disease has become incurable, treatment goals have become prolongation of survival and palliation of symptoms. Unfortunately, responses to systemic cytotoxic therapy lack dura- 
bility, and prognosis is inferior compared to other subtypes. ${ }^{75,99}$ Single agent chemotherapy is generally reasonable, but combination chemotherapy may be preferred in cases where immediate response is necessary (ie, visceral crisis). In analogy with the adjuvant setting, once breast cancer is metastatic, there is no evidence that some chemotherapeutic agents are superior to others in function of a particular breast cancer subtype. Single-agent chemotherapy options in TNBC include anthracyclines (doxorubicin, epirubicin, etc), taxanes (paclitaxel, docetaxel, etc), antimetabolites (capecitabine, gemcitabine), and other microtubule inhibitors, and/or stabilizers (vinorelbine, eribulin, ixabepilone). Platinum agents (cisplatin, carboplatin), for reasons mentioned before, may be of particular value in a subset of TNBC (those with BRCA-related dysfunctions). Several Phase II trials studied platinum salts in often heavily pretreated advanced breast cancer, showing only moderate $10 \%-30 \%$ response rates (irrespective of breast cancer phenotype). ${ }^{113-115}$ Further data in advanced TNBC are warranted. Combined chemotherapy regimens that have activity in anthracycline-pretreated patients, irrespective of breast cancer phenotype, include paclitaxel plus gemcitabine and docetaxel plus capecitabine. ${ }^{116,117}$ Adding ixabepilone (an antitubulin agent) to capecitabine improves response rates and progression-free survival, also in TNBC. ${ }^{118,119}$

\section{Targeted treatments}

Molecular processes and biological drivers that have been targeted in TNBC include vascular endothelial growth factor (VGEF), inefficient DNA repair mechanisms (ie, PARP), the epidermal growth factor (EGFR, also called HER-1), mammalian target of rapamycin (mTOR), Src oncogene pathway, histone deacetylase (HDAC), and androgen receptor. In general, clinical introduction of these molecules is hampered by a lack of predictive biomarkers.

The therapeutic role of angiogenesis inhibitors in (TN)BC remains uncertain. VEGF is associated with poor prognosis in breast cancer generally and with shorter survival in first-line metastatic TNBC. Despite improved progression-free survival and response rates, no overall survival was seen in any of the Phase III trials (E2100, AVADO, RIBBON-1) assessing the efficacy of bevacizumab (a humanized monoclonal antibody targeting VEGF). ${ }^{120-122}$ The clinical relevance of the significantly improved progression-free survival should therefore be questioned and the US Food and Drug Administration approval for use of this drug in breast cancer has been revoked. ${ }^{123}$ In the neoadjuvant setting, some data reveal only small clinical benefits but increased toxicity and cost from the addition of bevacizumab to cisplatinum, while the addition of bevacuzimab to anthracycline/taxane-based chemotherapy resulted in increased
pCR rates in the GeparQuinto study, confined to TNBC but not in the NSABP trial. ${ }^{124-126}$ Results from the randomized Phase III trial (BEATRICE) assessing the value of bevacuzimab in the adjuvant TNBC setting are awaited. ${ }^{127}$

PARP inhibitors are a novel class of agents of particular interest to treat TNBC, especially in those tumors showing altered BRCA functionality. High PARP expression has been reported in BRCA-1 associated and TNBC and PARP, a nuclear protein activated in the presence of DNA damage, is highly expressed in BRCA-1 related breast cancers that most likely are TNBC. PARP activity increases following radiotherapy/Chemotherapy-induced DNA damage. ${ }^{128,129}$ PARP is involved in several mechanisms essential in recovering from DNA damage and cancer growth. PARP inhibitors, in monotherapy or combined with chemo and or radiotherapy are therefore promising novel drugs that may enhance chemosensitivity and radiation sensitivity by inducing lethal DNA breaks that cannot be repaired in BRCA-deficient tumor cells, eventually resulting in cancer cell death. Several PARP inhibitors are in clinical development (ie, olaparib [AZD2281; AstraZeneca, London, UK], veliparib [ABT-888; Abbott, North Chicago, IL]), with promising results in BRCA1/2associated breast cancers of any subtype, but not so far in unselected non-BRCA-related TNBC. ${ }^{130-135}$ Although Phase II trials with iniparib (Sanofi-Aventis, Paris, France) found improved progression-free and overall survival with minimal toxicity, results remained unconfirmed in a subsequent larger Phase III trial. ${ }^{134}$ Methodological issues have been suggested, but molecular heterogeneity in TNBC may explain these results as well. ${ }^{102,136}$

EGFR/HER-1 is overexpressed in up to $70 \%$ of TNBC patients and has an important role in proliferation, migration, and protection against apoptosis. ${ }^{22,29,72,137}$ Moreover a subset of TNBC and basal-like breast cancers show EGFR1 gene amplification or chromosome 7 aneusomy. Nevertheless, only modest or clinical non-significant activity was found by using monoclonal antibodies (ie, cetuximab [Erbitux ${ }^{\circledR}$, ImClone, New York, NY]) against EGFR1. ${ }^{138-140}$ Effective selection strategies (biomarker development) are necessary to identify patients with TNBC that may truly benefit from these drugs.

Other potential targets in advanced TNBC currently being studied are mTOR, Src tyrosine kinase, and histone deacetylase (HDAC-i). mTOR is an effector of the PTEN/AKT/ IP3K pathway, often dysregulated in breast cancer and can be inhibited with Everolimus (Afinitor ${ }^{\circledR}$; RAD001, Novartis). ${ }^{141}$ Src tyrosine kinases are overexpressed in basal TNBC and promote receptor tyrosine kinase phosphorylation, affecting cell adhesion and migration. ${ }^{142}$ Dasatinib $\left(\right.$ Sprycel $^{\circledR}$, BMS- 
354825, Bristol-Myers Squibb, New York, NY) is an oral, small molecule tyrosine kinase inhibitor also affecting Src active in preclinical studies. ${ }^{143} \mathrm{HDAC}-\mathrm{i}$ work mainly through epigenetic mechanisms, by altering the acetylation status of the histonic proteins (that control the chromatine architecture), they influence the expression of key genes such as ER in breast carcinomas. Thus, administration of HDAC-i may result in re-expression of functional ER mRNA and protein, in ER-negative breast cancer. ${ }^{144}$ A proportion of TNBC express androgen receptors and molecular studies recently distinguished a TNBC phenotype enriched in androgenic pathways..$^{31} \mathrm{~A}$ Phase II trial assessing the value of the antiandrogen bicalutamide in metastatic TNBC is underway (NCT00468715).

\section{Conclusion}

TNBC is a heterogeneous disease comprehending different orphan breast cancers simply defined by the absence of ER/ PR/HER-2. Some TNBC are very chemosensitive as can be seen from neoadjuvant data, and the majority of patients confronted with and treated for TNBC will never relapse. Those patients experiencing metastatic relapses usually do so within 5 years following surgery. Metastatic survival is shorter compared to other subtypes, and treatment options are few and responses lack durability. Novel promising drug targets are being studied, but the discovery of reliable predictive biomarkers is imperative before these novel treatments can be translated into the clinic. Molecular studies are teaching us that TNBC constitutes different biological diseases.

\section{Disclosure}

All authors report no conflicts of interest in this work.

\section{References}

1. Jemal A, Bray F, Center MM, Ferlay J, Ward E, Forman D. Global cancer statistics. CA Cancer J Clin. 2011;61(2):69-90.

2. Surveillance Epidemiology and End Results (SEER). Lifetime risk of developing or dying of cancer [webpage on the Internet]. Bethesda, MD: Surveillance Research Program; nd. Available from: http://seer.cancer. gov/statistics/types/lifetimerisk.html. Accessed May 15, 2012.

3. Perou CM, Sorlie T, Eisen MB, et al. Molecular portraits of human breast tumours. Nature. 2000;406(6797):747-752.

4. Goldhirsch A, Wood WC, Coates AS, Gelber RD, Thürlimann B, Senn HJ; Panel members. Strategies for subtypes-dealing with the diversity of breast cancer: highlights of the St Gallen International Expert Consensus on the Primary Therapy of Early Breast Cancer 2011. Ann Oncol. 2011;22(8):1736-1747.

5. Layfield LJ, Gupta D, Mooney EE. Assessment of tissue estrogen and progesterone receptor levels: a survey of current practice, techniques, and quantitation methods. Breast J. 2000;6(3):189-196.

6. Putti TC, Pinder SE, Elston CW, Lee AH, Ellis IO. Breast pathology practice: most common problems in a consultation service. Histopathology. 2005;47(5):445-457.
7. Dowsett M, Cuzick J, Wale C, Howell T, Houghton J, Baum M. Retrospective analysis of time to recurrence in the ATAC trial according to hormone receptor status: an hypothesis-generating study. J Clin Oncol. 2005;23(30):7512-7517.

8. Regitnig P, Reiner A, Dinges HP, et al. Quality assurance for detection of estrogen and progesterone receptors by immunohistochemistry in Austrian pathology laboratories. Virchows Arch. 2002;441(4): 328-334.

9. Eiermann W, Paepke S, Appfelstaedt J, et al; Letrozole Neo-Adjuvant Breast Cancer Study Group. Letrozole neo-adjuvant breast cancer study group. Preoperative treatment of postmenopausal breast cancer patients with letrozole: a randomized double-blind multicenter study. Ann Oncol. 2001;12(11):1527-1532.

10. Stendahl M, Rydén L, Nordenskjöld B, Jönsson PE, Landberg G, Jirström K. High progesterone receptor expression correlates to the effect of adjuvant tamoxifen in premenopausal breast cancer patients. Clin Cancer Res. 2006;12(15):4614-4618.

11. Hammond ME, Hayes DF, WolffAC, Mangu PB, Temin S. American society of clinical oncology/college of american pathologists guideline recommendations for immunohistochemical testing of estrogen and progesterone receptors in breast cancer. J Oncol Pract. 2010;6(4): 195-197.

12. McCullough AE, Dell'Orto P, Reinholz MM, et al. Concordance of HER2 central assessment by two international central laboratories: a ring study within the framework of the adjuvant HER2-positive ALTTO trial (BIG2-06/N063D/EGF106708). Cancer Res. 2010;70(Suppl):abst P3-10-36.

13. Allred DC. Issues and updates: evaluating estrogen receptor-alpha, progesterone receptor, and HER2 in breast cancer. Mod Pathol. 2010;23 Suppl 2:S52-S59.

14. Nagle RB, Böcker W, Davis JR, et al. Characterization of breast carcinomas by two monoclonal antibodies distinguishing myoepithelial from luminal epithelial cells. J Histochem Cytochem. 1986;34(7): 869-881.

15. Dairkee SH, Puett L, Hackett AJ. Expression of basal and luminal epithelium-specific keratins in normal, benign, and malignant breast tissue. J Natl Cancer Inst. 1988;80(9):691-695.

16. Pintens S, Neven P, Drijkoningen $M$, et al. Triple negative breast cancer: a study from the point of view of basal CK5/6 and HER-1. J Clin Pathol. 2009;62(7):624-628.

17. Ciocca DR, Gago FE, Fanelli MA, Calderwood SK. Co-expression of steroid receptors (estrogen receptor alpha and/or progesterone receptors) and Her-2/neu: Clinical implications. J Steroid Biochem Mol Biol. 2006;102(1-5):32-40.

18. Carey LA, Perou CM, Livasy CA, et al. Race, breast cancer subtypes, and survival in the Carolina Breast Cancer Study. JAMA. 2006;295(21): 2492-2502.

19. Nielsen TO, Hsu FD, Jensen K, et al. Immunohistochemical and clinical characterization of the basal-like subtype of invasive breast carcinoma. Clin Cancer Res. 2004;10:5367-5374.

20. Cuzick J, Dowsett M, Wale C, et al. Prognostic value of a combined ER, PgR, Ki67, HER2 immunohistochemical (IHC4) score and comparison with the GHI recurrence score - results from TransATAC. Cancer Res. 2009;69 Suppl 24:abst 74.

21. Rakha EA, Elsheikh SE, Aleskandarany MA, et al. Triple-negative breast cancer: distinguishing between basal and nonbasal subtypes. Clin Cancer Res. 2009;15:2302-2310.

22. Kreike B, van Kouwenhove M, Horlings H, et al. Gene expression profiling and histopathological characterization of triple-negative/ basal-like breast carcinomas. Breast Cancer Res. 2007;9:R65.

23. Rakha EA, El-Sayed ME, Green AR, Lee AH, Robertson JF, Ellis IO. Prognostic markers in triple negative breast cancer. Cancer. 2007;109:25-32.

24. Cheang MC, Voduc D, Bajdik C, et al. Basal-like breast cancer defined by five biomarkers has superior prognostic value than triple-negative phenotype. Clin Cancer Res. 2008;14:1368-1376.

25. Sasa M, Bando Y, Takahashi M, Hirose T, Nagao T. Screening for basal marker expression is necessary for decision of therapeutic strategy for triple-negative breast cancer. J Surg Oncol. 2008;97:30-34. 
26. Dabbs DJ, Chivukula M, Carter G, Bhargava R. Basal phenotype of ductal carcinoma in situ: recognition and immunohistologic profile. Mod Pathol. 2006;19:1506-1511.

27. Perou CM. Molecular stratification of triple-negative breast cancers. Oncologist. 2010;15 Suppl 5:39-48.

28. Parker JS, Mullins M, Cheang MC, et al. Supervised risk predictor of breast cancer based on intrinsic subtypes. J Clin Oncol. 2009;27:1160-1167.

29. Bertucci F, Finetti P, Cervera N, et al. How basal are triple-negative breast cancers? Int J Cancer. 2008;123:236-240.

30. de Ronde JJ, Hannemann J, Halfwerk H, et al. Concordance of clinical and molecular breast cancer subtyping in the context of preoperative chemotherapy response. Breast Cancer Res Treat. 2010;119:119-126.

31. Lehman BD, Bauer JA, Chen X, et al. Transcriptome analysis of triple negative breast cancers identifies six distinct biological subgroups and reveals therapeutic strategies. Cancer Res. 2010;70:24s Suppl:abst PD01-07.

32. Bauer KR, Brown M, Cress RD, Parise CA, Caggiano V. Descriptive analysis of estrogen receptor (ER)-negative, progesterone receptor (PR)-negative, and HER2-negative invasive breast cancer, the so-called triple-negative phenotype: a population-based study from the California cancer Registry. Cancer. 2007;109(9):1721-1728.

33. Morris GJ, Naidu S, Topham AK, et al. Differences in breast carcinoma characteristics in newly diagnosed African-American and Caucasian patients: A single-institution compilation compared with the National Cancer Institute's Surveillance, Epidemiology, and End Results database. Cancer. 2007;110:876-884.

34. Stead LA, Lash TL, Sobieraj JE, et al. Triple negative breast cancers are increased in black women regardless of age or body mass index. Breast Cancer Res. 2009;11(2):R18.

35. Lund MJ, Trivers KF, Porter PL, et al. Race and triple negative threats to breast cancer survival: A population-based study in Atlanta, GA. Breast Cancer Res Treat. 2009;113:357-370.

36. Millikan RC, Newman B, Tse CK, et al. Epidemiology of basal-like breast cancer. Breast Cancer Res Treat. 2008;109(1):123-139.

37. Foulkes WD, Stefansson IM, Chappuis PO, et al. Germline BRCA1 mutations and a basal epithelial phenotype in breast cancer. $J$ Natl Cancer Inst. 2003;95:1482-1485.

38. Evans DG, Howell A. Are we ready for online tools in decision making for BRCA1/2 mutation carriers? J Clin Oncol. 2012;30(5): 471-473.

39. Antoniou AC, Beesley J, McGuffog L, et al; CIMBA. Common breast cancer susceptibility alleles and the risk of breast cancer for BRCA1 and BRCA2 mutation carriers: Implications for risk prediction. Cancer Res. 2010;70:9742-9754.

40. Rakha EA, Reis-Filho JS, Ellis IO. Basal-like breast cancer: a critical review. J Clin Oncol. 2008;26:2568-2581.

41. Reis-Filho JS, Tutt AJ. Triple negative tumours: a critical review. Histopathology. 2008;52:108-118.

42. Armes JE, Venter DJ. The pathology of inherited breast cancer. Pathology. 2002;34(4):309-314.

43. Fulford LG, Easton DF, Reis-Filho JS, et al. Specific morphological features predictive for the basal phenotype in grade 3 invasive ductal carcinoma of the breast. Histopathology. 2006;49:22-34.

44. Young S, Pilarski R, Donenburg T, et al. The prevalence of BRCA mutations among young women with triple-negative breast cancer. BMC Cancer. 2009;9:86.

45. Kwon JS, Gutierrez-Barrera AM, Young D, et al. Expanding the criteria for BRCA mutation testing in breast cancer survivors. $J$ Clin Oncol. 2010;28:4214-4220.

46. Futreal PA, Liu Q, Shattuck-Eidens D, et al. BRCA1 mutations in primary breast and ovarian carcinomas. Science. 1994;266:120-122.

47. Lancaster JM, Cochran CJ, Brownlee HA, et al. Detection of BRCA1 mutations in women with early-onset ovarian cancer by use of the protein truncation test. J Natl Cancer Inst. 1996;88:552-554.

48. Esteller M, Sparks A, Toyota M, et al. Analysis of adenomatous polyposis coli promoter hypermethylation in human cancer. Cancer Res. 2000;60:4366-4371.
49. Baldwin RL, Nemeth E, Tran H, et al. BRCA1 promoter region hypermethylation in ovarian carcinoma: a population-based study. Cancer Res. 2000;60:5329-5333.

50. Grushko TA, Nwachukwu N, Charoenthammaraksa S, et al. Evaluation of BRCA1 inactivation by promoter methylation as a marker of triple-negative and basal-like breast cancers. J Clin Oncol. 2010;28(Suppl):abst 10510.

51. Turner N, Tutt A, Ashworth A. Hallmarks of 'BRCAness' in sporadic cancers. Nat Rev Cancer. 2004;4:814-819.

52. Turner NC, Reis-Filho JS, Russell AM, et al. BRCA1 dysfunction in sporadic basal-like breast cancer. Oncogene. 2007;14:2126-2132.

53. Phipps A, Malone K, Porter P, Daling JR, Li CI. Reproductive and hormonal risk factors for postmenopausal luminal, Her-2-overexpressing, and triple-negative breast cancer. Cancer. 2008;113:1521-1526.

54. Yang X, Sherman M, Rimm D, et al. Differences in risk factors for breast cancer molecular subtypes in a population-based study. Cancer Epidemiol Biomarkers Prev. 2007;16:439-443.

55. Dent R, Trudeau M, Pritchard KI, et al. Triple-negative breast cancer: clinical features and patterns of recurrence. Clin Cancer Res. 2007;13: $4429-4434$

56. Collett K, Stefansson IM, Eide J, et al. A basal epithelial phenotype is more frequent in interval breast cancers compared with screen detected tumors. Cancer Epidemiol Biomarkers Prev. 2005;14:1108-1112.

57. Yang WT, Dryden M, Broglio K, et al. Mammographic features of triple receptor-negative primary breast cancers in young premenopausal women. Breast Cancer Res Treat. 2008;111:405-410.

58. Wang Y, Ikeda DM, Narasimhan B, et al. Estrogen receptor negative invasive breast cancer: imaging features of tumors with and without human epidermal growth factor receptor type 2 overexpression. Radiology. 2008;246:367-375.

59. Kim SH, Seo BK, Lee J, et al. Correlation of ultrasound findings with histology, tumor grade, and biological markers in breast cancer. Acta Oncol. 2008:47:1531-1538.

60. Basu S, Chen W, Tchou J, et al. Comparison of triple negative and estrogen receptor-positive/progesterone receptorpositive/ HER2negative breast carcinoma using quantitative fluorine-18 fluorodeoxyglucose/positron emission tomography imaging parameters: a potentially useful method for disease characterization. Cancer. 2008;112: 995-1000.

61. Thike AA, Cheok PY, Jara-Lazaro AR, Tan B, Tan P, Tan PH. Triple-negative breast cancer: clinicopathological characteristics and relationship with basal-like breast cancer. Mod Pathol. 2010;23: $123-133$

62. Tognon C, Knezevich SR, Huntsman D, et al. Expression of the ETV6-NTRK3 gene fusion as a primary event in human secretory breast carcinoma. Cancer Cell. 2002;2(5):367-376.

63. Persson M, Andrén Y, Mark J, Horlings HM, Persson F, Stenman G. Recurrent fusion of MYB and NFIB transcription factor genes in carcinomas of the breast and head and neck. Proc Natl Acad Sci U S A. 2009;106(44):18740-18744.

64. Azoulay S, Laé M, Fréneaux P, et al. KIT is highly expressed in adenoid cystic carcinoma of the breast, a basal-like carcinoma associated with a favorable outcome. Mod Pathol. 2005;18:1623-1631.

65. Fourquet A, Vilcoq JR, Zafrani B, Schlienger P, Jullien D, Campana F. Medullary breast carcinoma: the role of radiotherapy as primary treatment. Radiother Oncol. 1987;10:1-6.

66. Dendale R, Vincent-Salomon A, Mouret-Fourme E, et al. Medullary breast carcinoma: prognostic implications of p53 expression. Int J Biol Markers. 2003;18:99-105.

67. Huober JB, Gelber S, Thurlimann B, et al. Prognosis of medullary breast cancer: Analyses of 13 International Breast Cancer Study Group (IBCSG) trials. J Clin Oncol. 2010;28 Suppl:abst 630.

68. Hennessy BT, Giordano S, Broglio K, et al. Biphasic metaplastic sarcomatoid carcinoma of the breast. Ann Oncol. 2006;17:605-613.

69. Piccart M, Viale G, Ellis P, Abramowicz M, Carey L. Tips and tricks in triple-negative breast cancer: how to manage patients in real-life practice? Ecancermedicalscience. 2011;5:217. 
70. Kusinska R, Potemski P, Jesionek-Kupnicka D, Kordek R. Immunohistochemical identification of basal-type cytokeratins in invasive ductal breast carcinoma relation with grade, stage, estrogen receptor and HER2. Pol J Pathol. 2005;56:107-110.

71. Crabb SJ, Cheang MC, Leung S, et al. Basal breast cancer molecular subtype predicts for lower incidence of axillary lymph node metastases in primary breast cancer. Clin Breast Cancer. 2008;8:249-256.

72. Tan DS, Marchió C, Jones RL, et al. Triple negative breast cancer: molecular profiling and prognostic impact in adjuvant anthracyclinetreated patients. Breast Cancer Res Treat. 2008;111:27-44.

73. Foulkes WD, Metcalfe K, Hanna W, et al. Disruption of the expected positive correlation between breast tumor size and lymph node status in BRCA-1 related breast carcinoma. Cancer. 2003;98:1569-1577.

74. Jatoi I, Anderson WF, Jeong JH, Redmond CK. Breast cancer adjuvant therapy: time to consider its time-dependent effects. J Clin Oncol. 2011;29(17):2301-2304.

75. Kennecke H, Yerushalmi R, Woods R, et al. Metastatic behavior of breast cancer subtypes. J Clin Oncol. 2010;28(20):3271-3277.

76. Freedman G, Anderson P, Li T, Nicolaou N. Locoregional recurrence of triple-negative breast cancer after breast-conserving surgery and radiation. Cancer. 2009;115:946-951.

77. Voduc KD, Cheang MC, Tyldesley S, Gelmon K, Nielsen TO, Kennecke H. Breast cancer subtypes and the risk of local and regional relapse. J Clin Oncol. 2010;28(10):1684-1691.

78. Lowery AJ, Kell MR, Glynn RW, Kerin MJ, Sweeney KJ. Locoregional recurrence after breast cancer surgery: a systematic review by receptor phenotype. Breast Cancer Res Treat. 2012;133(3):831-841.

79. Montagna E, Bagnardi V, Rotmensz N, et al. Breast cancer subtypes and outcome after local and regional relapse. Ann Oncol. 2012;23(2):324-331.

80. Liedtke C, Mazouni C, Hess KR, et al. Response to neoadjuvant therapy and long-term survival in patients with triple-negative breast cancer. J Clin Oncol. 2008;26:1275-1281.

81. Smid M, Wang Y, Zhang Y, et al. Subtypes of breast cancer show preferential site of relapse. Cancer Res. 2008;68:3108-3114.

82. Lin NU, Bellon JR, Winer EP. CNS metastases in breast cancer. J Clin Oncol. 2004;22(17):3608-3617.

83. Heitz F, Harter P, Traut A, et al. Cerebral metastases (CM) in breast cancer (BC) with focus on triple-negative tumors. J Clin Oncol. 2008;26; Suppl:abst 1010

84. Dawood S, Broglio K, Esteva FJ, et al. Survival among women with triple receptor-negative breast cancer and brain metastases. Ann Oncol. 2009;20:621-627.

85. Desmedt C, Haibe-Kains B, Wirapati P, et al. Biological processes associated with breast cancer clinical outcome depend on the molecular subtypes. Clin Cancer Res. 2008;14:5158-5165.

86. Keam B, Im SA, Lee KH, et al. Ki-67 can be used for further classification of triple negative breast cancer into two subtypes with different response and prognosis. Breast Cancer Res. 2011;13(2):R22.

87. Aleskandarany MA, Green AR, Benhasouna AA, et al. Prognostic value of proliferation assay in the luminal, HER2-positive, and triple-negative biologic classes of breast cancer. Breast Cancer Res. 2012;14(1):R3.

88. Cancello G, Maisonneuve P, Rotmensz N, et al. Prognosis in women with small (T1 mic,T1a,T1b) node-negative operable breast cancer by immunohistochemically selected subtypes. Breast Cancer Res Treat. 2011;127(3):713-720.

89. Albergaria A, Ricardo S, Milanezi F, et al. Nottingham Prognostic Index in triple-negative breast cancer: a reliable prognostic tool? BMC Cancer. 2011;11:299.

90. Tang D, Xu S, Zhang Q, Zhao W. The expression and clinical significance of the androgen receptor and E-cadherin in triple-negative breast cancer. Med Oncol. 2012;29(2):526-533.

91. Kashiwagi S, Yashiro M, Takashima T, et al. Significance of E-cadherin expression in triple-negative breast cancer. Br J Cancer. 2010;103(2): 249-255.

92. Viale G, Rotmensz N, Maisonneuve P, et al. Invasive ductal carcinoma of the breast with the "triple-negative" phenotype: prognostic implications of EGFR immunoreactivity. Breast Cancer Res Treat. 2009; 116(2):317-328.
93. Mohammed RA, Ellis IO, Mahmmod AM, et al. Lymphatic and blood vessels in basal and triple-negative breast cancers: characteristics and prognostic significance. Mod Pathol. 2011;24(6):774-785.

94. Prat A, Parker JS, Karginova O, et al. Phenotypic and molecular characterization of the claudinlow intrinsic subtype of breast cancer. Breast Cancer Res. 2010;12:R68.

95. Ono M, Tsuda H, Shimizu C, et al. Tumor-infiltrating lymphocytes are correlated with response to neoadjuvant chemotherapy in triplenegative breast cancer. Breast Cancer Res Treat. 2012;132(3): 793-805.

96. Desmedt C, Di Leo A, de Azambuja E, et al. Multifactorial approach to predicting resistance to anthracyclines. J Clin Oncol. 2011;29: $1578-1586$

97. von Minckwitz G, Untch M, Blohmer JU, et al. Definition and impact of pathologic complete response on prognosis after neoadjuvant chemotherapy in various intrinsic breast cancer subtypes. J Clin Oncol. 2012;30(15):1796-1804

98. Rouzier R, Perou CM, Symmans WF, et al. Breast cancer molecular subtypes respond differently to preoperative chemotherapy. Clin Cancer Res. 2005;11(16):5678-5685.

99. Carey LA, Dees EC, Sawyer L, et al. The triple negative paradox: primary tumor chemosensitivity of breast cancer subtypes. Clin Cancer Res. 2007;13(8):2329-2334.

100. Straver ME, Glas AM, Hannemann J, et al. The 70-gene signature as a response predictor for neoadjuvant chemotherapy in breast cancer. Breast Cancer Res Treat. 2010;119(3):551-558.

101. Schott AF, Hayes DF. Defining the benefits of neoadjuvant chemotherapy for breast cancer. J Clin Oncol. 2012;30(15):1747-1749.

102. Metzger-Filho O, Tutt A, de Azambuja E, et al. Dissecting the heterogeneity of triple-negative breast cancer. J Clin Oncol. 2012;30(15): 1879-1887.

103. Di Leo A, Desmedt C, Bartlett JM, et al. Final results of a metaanalysis testing HER2 and topoisomerase IIal pha genes as predictors of incremental benefit from anthracyclines in breast cancer. J Clin Oncol. 2010;28:72s Suppl:abst 519.

104. Rocca A, Paradiso A, Sismondi P, et al. Benefit from CMF with or without anthracyclines in relation to biologic profiles in early breast cancer. J Clin Oncol. 2011;29:87s Suppl:abst 1031.

105. De Laurentiis M, Cancello G, D'Agostino D, et al. Taxane-based combinations as adjuvant chemotherapy of early breast cancer: A metaanalysis of randomized trials. J Clin Oncol. 2008;26(1): 44-53.

106. Early Breast Cancer Trialists' Collaborative Group (EBCTCG); Peto R, Davies C, Godwin J, et al. Comparisons between different polychemotherapy regimens for early breast cancer: meta-analyses of long-term outcome among 100,000 women in 123 randomised trials. Lancet. 2012;379(9814):432-444.

107. Isakoff SJ. Triple-negative breast cancer: role of specific chemotherapy agents. Cancer J. 2010;16:53-61.

108. Gronwald J, Byrski T, Huzarski T, et al. Neoadjuvant therapy with cisplatin in BRCA1-positive breast cancer patients. J Clin Oncol. 2009;27:7s Suppl:abst 502.

109. Byrski T, Huzarski T, Dent R, et al. Response to neoadjuvant therapy with cisplatin in BRCA1-positive breast cancer patients. Breast Cancer Res Treat. 2009;115:359-363.

110. Byrski T, Gronwal dJ, Huzarski T, et al. Pathologic complete response rates in young women with BRCA1-positive breast cancers after neoadjuvant chemotherapy. J Clin Oncol. 2010;28: 375-379.

111. Alba E, Chacon J, Lluch A, et al. Chemotherapy (CT) with or without carboplatin as neoadjuvant treatment in patients with basal-like breast cancer: GEICAM 2006-2003-A multicenter, randomized phase II study. J Clin Oncol. 2011;29:83s Suppl:abst 1015.

112. Amir E, Miller N, Geddie W, et al. Prospective study evaluating the impact of tissue confirmation of metastatic disease in patients with breast cancer. J Clin Oncol. 2012;30(6):587-592.

113. Forastiere AA, Hakes TB, Wittes JT, Wittes RE. Cisplatin in the treatment of metastatic breast carcinoma: A prospective randomized trial of two dosage schedules. Am J Clin Oncol. 1982;5(3): 243-247. 
114. Sledge GW Jr, Loehrer PJ Sr, Roth BJ, Einhorn LH. Cisplatin as first-line therapy for metastatic breast cancer. J Clin Oncol. 1988;6(12): 1811-1814.

115. O'Brien ME, Talbot DC, Smith IE. Carboplatin in the treatment of advanced breast cancer: a phase II study using a pharmacokinetically guided dose schedule. J Clin Oncol. 1993;11(11):2112-2117.

116. Albain KS, Nag SM, Calderillo-Ruiz G, et al. Gemcitabine plus Paclitaxel versus Paclitaxel monotherapy in patients with metastatic breast cancer and prior anthra ycline treatment. J Clin Oncol. 2008;26(24): 3950-3957.

117. O'Shaughnessy J, Miles D, Vukelja S, et al. Superior survival with capecitabine plus docetaxel combination therapy in anthracycline pretreated patients with advanced breast cancer: phase III trial results. J Clin Oncol. 2002;20(12):2812-2823.

118. Thomas ES, Gomez HL, Li RK, et al. Ixabepilone plus capecitabine for metastatic breast cancer progressing after anthracycline and taxane treatment. J Clin Oncol. 2007;25(33):5210-5217.

119. Perez EA, Patel T, Moreno-Aspitia A. Efficacy of ixabepilone in ER/ PR/HER2-negative (triple-negative) breast cancer. Breast Cancer Res Treat. 2010;121(2):261-271.

120. Miller K, Wang M, Gralow J, et al. Paclitaxel plus bevacizumab versus paclitaxel alone for metastatic breast cancer. N Engl J Med. 2007;357: 2666-2676.

121. Miles DW, Chan A, Dirix LY, et al. Phase III study of bevacizumab plus docetaxel compared with plac ebo plus docetaxel for the firstline treatment of human epidermal growth factor receptor 2-negative metastatic breast cancer. J Clin Oncol. 2010;28:3239-3247.

122. O'Shaughnessy JA, Brufsky AM. RiBBON 1 and RiBBON 2: phase III trials of bevacizumab with standard chemotherapy for metastatic breast cancer. Clin Breast Cancer. 2008;8:370-373.

123. FDA pulls approval for avastin in breast cancer. Cancer Discov. 2011;1(7):OF1-OF2. Epub November 23, 2011.

124. Ryan PD, Tung NM, Isakoff M, et al. Neoadjuvant cisplatin and bevacizumab in triple negative breast cancer (TNBC): safety and efficacy. J Clin Oncol. 2009;27:15s Suppl:abst 551.

125. Gerber B, Eidtmann H, Rezai M, et al. Neoadjuvant bevacizumab and anthracycline-taxane-based chemotherapry in 686 triple-negative primary breast cancers: Secondary endpoint analysis of the GeparQuinto study (GBG 44). J Clin Oncol. 2011;29:81s:abst 1006.

126. Bear HD, Tang G, Rastogi $P$, et al. The effect on pCR of bevacizumab and/or antimetabolites added to standard neoadjuvant chemotherapy: NSABP protocol B-40. J Clin Oncol. 2011;29:abst LBA 1005.

127. Hoffmann-La Roche. BEATRICE Study: a study of avastin (bevacizumab) adjuvant therapy in triple negative breast cancer. In: ClinicalTrials.gov [website on the Internet]. Bethesda, MD: US National Library of Medicine; 2011 [updated August 15, 2012]. Available from: http:// clinicaltrials.gov/ct2/show/NCT00528567. Accessed May 15, 2012.

128. Hashimoto K, Tamura K. Breakthrough breast cancer treatment-Parp inhibitor, BRCA, and triple negative breast cancer. Gan To Kagaku Ryoho. 2010;37:1187-1191. [Japanese].

129. Ratnam K, Low JA. Current development of clinical inhibitors of poly(ADP-ribose) polymerase in oncology. Clin Cancer Res. 2007;13: 1383-1388.

130. Fong PC, Boss DS, Yap TA, et al. Inhibition of poly (ADP-ribose) polymerase in tumors from BRCA mutation carriers. $N$ Engl $J$ Med. 2009;361:123-134.
131. Isakoff SJ, Overmoyer B, Tung NM, et al. A phase II trial of the PARP inhibitor veliparib (ABT888) and temozolomide for metastatic breast cancer. J Clin Oncol. 2010;28:abst 1019.

132. Tutt A, Robson M, Garber JE, et al. Oral poly(ADP-ribose) polymerase inhibitor olaparib in patients with BRCA1 or BRCA2 mutations and advanced breast cancer: a proof-of-concept trial. Lancet. 2010; 376(9737):235-244.

133. Gelmon KA, Tischkowitz M, Mackay H, et al. Olaparib in patients with recurrent high-grade serous or poorly differentiated ovarian carcinoma or triple-negative breast cancer: a phase 2, multicentre, open-label, non-randomised study. Lancet Oncol. 2011;12(9):852-861.

134. O'Shaughnessy J, Schwartzberg LS, Danso MA, et al. A randomized phase III study of iniparib (BSI-201) in combination with gemcitabine/ carboplatin (G/C) in metastatic triple-negative breast cancer (TNBC). J Clin Oncol. 2011;29:abst 1007.

135. Dent RA, Lindeman GJ, Clemons M, et al. Safety and efficacy of the oral PARP inhibitor olaparib (AZD2281) in combination with paclitaxel for the first- or second-line treatment of patients with metastatic triple-negative breast cancer: results from the safety cohort of a phase I/II multicenter trial. J Clin Oncol. 2010;28:abst 1018.

136. Gelmon K, Dent R, Mackey JR, Laing K, McLeod D, Verma S. Targeting triple-negative breast cancer: optimising therapeutic outcomes. Ann Oncol. 2012. [Epub ahead of print.]

137. Tsutsui S, Ohno S, Murakami S, Hachitanda Y, Oda S. Prognostic value of epidermal growth factor receptor (EGFR) and its relationship to the estrogen receptor status in 1029 patients with breast cancer. Breast Cancer Res Treat. 2002;71:67-75.

138. Baselga J, Stemmer S, Pego A, et al. Cetuximab + cisplatin in estrogen receptor-negative, progesterone receptor-negative, HER2-negative (triple-negative) metastatic breast cancer: results of the randomized phase II BALI-1 trial. Cancer Res. 2010;70:abst PD01-01.

139. O'Shaughnessy J, Weckstein D, Vukelja S, et al. Preliminary results of a randomized phase II study of weekly irinotecan/carboplatin with or without cetuximab in patients with metastatic breast cancer. Breast Cancer Res Treat. 2007;106:S32:abst 308.

140. Carey LA, Rugo HS, Marcom PK, et al. TBCRC 001: EGFR inhibition with cetuximab added to carboplatin in metastatic triple-negative (basal-like) breast cancer. J Clin Oncol. 2008;26:abst 1009.

141. Faivre S, Kroemer G, Raymond E. Current development of mTOR inhibitors as anticancer agents. Nat Rev Drug Discov. 2006;5(8): 671-688.

142. Hochgräfe F, Zhang L, O'Toole SA, et al. Tyrosine phosphorylation profiling reveals the signaling network characteristics of basal breast cancer cells. Cancer Res. 2010;70:9391-9401.

143. Finn RS, Dering J, Ginther C, et al. Dasatinib, an orally active small molecule inhibitor of both the src and abl kinases, selectively inhibits growth of basal-type/"triple-negative" breast cancer cell lines growing in vitro. Breast Cancer Res Treat. 2007;105(3):319-326.

144. Lacevic M, Minton S, Schmitt M, et al. Phase II trial of the HDAC inhibitor, vorinostat, in combination with tamoxifen for patients with advanced breast cancer who have failed prior antihormonal therapy. Breast Cancer Res Treat. 2007;106 Suppl 1:abst 2097.
International Journal of Women's Health

\section{Publish your work in this journal}

The International Journal of Women's Health is an international, peerreviewed open-access journal publishing original research, reports, reviews and commentaries on all aspects of women's healthcare including gynecology, obstetrics, and breast cancer. Subject areas include: Chronic conditions (migraine headaches, arthritis, osteoporosis);

\section{Dovepress}

Endocrine and autoimmune syndromes; Sexual and reproductive health; Psychological and psychosocial conditions. The manuscript management system is completely online and includes a very quick and fair peer-review system. Visit http://www.dovepress.com/ testimonials.php to read real quotes from published authors. 